Journal of Patient-Centered

Volume 5

Issue 4 - Patient Self-Management

Article 2

$10-29-2018$

\title{
Impact of a Boot Camp Translation Intervention on Self- Management Support in Primary Care
}

\author{
Donald E. Nease Jr. \\ Jeanette M. Daly \\ L. Miriam Dickinson \\ Douglas H. Fernald \\ David L. Hahn \\ Barcey T. Levy \\ LeAnn C. Michaels \\ Matthew J. Simpson \\ John M. Westfall \\ Lyle J. Fagnan
}

Follow this and additional works at: https://aah.org/jpcrr

Part of the Diseases Commons, Health Services Research Commons, Primary Care Commons, and the Public Health Education and Promotion Commons

\section{Recommended Citation}

Nease DE Jr, Daly JM, Dickinson LM, Fernald DH, Hahn DL, Levy BT, Michaels LC, Simpson MJ, Westfall JM, Fagnan LJ. Impact of a boot camp translation intervention on self-management support in primary care. J Patient Cent Res Rev. 2018;5:256-66. doi: 10.17294/2330-0698.1635

Published quarterly by Midwest-based health system Advocate Aurora Health and indexed in PubMed Central, the Journal of Patient-Centered Research and Reviews (JPCRR) is an open access, peer-reviewed medical journal focused on disseminating scholarly works devoted to improving patient-centered care practices, health outcomes, and the patient experience. 


\title{
Impact of a Boot Camp Translation Intervention on Self-Management Support in Primary Care
}

\author{
A Report From the INSTTEPP* Trial and Meta-LARC' Consortium
}

\author{
Donald E. Nease, Jr., MD, ${ }^{1}$ Jeanette M. Daly, PhD, RN, ${ }^{2}$ L. Miriam Dickinson, PhD, ${ }^{1}$ Douglas H. \\ Fernald, MA, ${ }^{1}$ David L. Hahn, MD,${ }^{3}$ Barcey T. Levy, MD, PhD, ${ }^{2}$ LeAnn C. Michaels, BS, ${ }^{4}$ Matthew J. \\ Simpson, MD, ${ }^{1}$ John M. Westfall, MD, ${ }^{1}$ Lyle J. Fagnan, $\mathrm{MD}^{4}$ \\ ${ }^{1}$ Department of Family Medicine, University of Colorado School of Medicine, Aurora, CO; ${ }^{2}$ Department of Family \\ Medicine, University of lowa, lowa City, IA; ${ }^{3}$ Department of Family Medicine and Community Health, University of \\ Wisconsin School of Medicine and Public Health, Madison, WI; ${ }^{4}$ Department of Family Medicine, Oregon Health \& \\ Science University, Portland, OR
}
Purpose Self-management support (SMS) is a pillar of the well-established chronic care model and a key component of improving outcomes for patients with chronic illnesses. The Implementing Networks' Self- management Tools Through Engaging Patients and Practices (INSTTEPP) trial sought to determine whether a boot camp translation process could assist small to medium-sized primary care practices with care managers implement SMS tools.

Methods INSTTEPP used a stepped-wedge design across 16 practices from 4 practice-based research networks over 12 months. Each network completed a 2-month boot camp translation for creating SMS tools with 16 participants ( 2 patients, a clinician, and a care manager from each of 4 practices) and subsequent implementation. Outcome measures for patients were the Patient Activation Measure (PAM), self-rated health, and Patient Assessment of Chronic Illness Care (PACIC) process-of-care items at baseline, 1 and 2 months. Clinician Support for Patient Activation Measure (CS-PAM) and theory of planned behavior outcomes were assessed at 5 points over 10 months for clinicians and staff.

Results A total of 297 patients and 89 practice staff and clinicians completed surveys during the study. Over successive 2-month sampling periods, intervention patients experienced greater improvement in PACIC process of care and self-rated health compared to control patients $(P<0.0001$ and $P=0.0273$, respectively). PAM $(P=0.3515)$, CS-PAM $(P=0.7464)$, and theory of planned behavior outcomes $(P>0.10$ for all) were not significantly different.

Conclusions Significant effects on process of care and self-rated health are evidence that the boot camp translation intervention impacted SMS. A larger trial with a typical 6-month boot camp intervention may show significant effects on other outcomes. (J Patient Cent Res Rev. 2018;5:256-266.)

Keywords self-management; patient engagement; primary care; boot camp translation; chronic disease

\footnotetext{
*Implementing Networks Self-management Tools Through Engaging Patients and Practices

tThe Meta-Network Learning and Research Center is comprised of Duke Primary Care Research Consortium, lowa Research Network, Oregon Rural Practice-based Research Network, Quebec Practice-Based Research Network, State Networks of Colorado Ambulatory Practices and Partners, and Wisconsin Research and Education Network.

Correspondence: Donald E. Nease, Jr., MD,

University of Colorado School of Medicine, 12631 E. 17th Avenue, F496, Aurora, CO 80045 (donald.nease@ucdenver.edu)
}

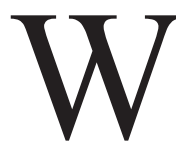

ith almost one-half of Americans projected to have at least one chronic condition before 2020, it is paramount that the health care system reduce the burden to primary care for disease management by facilitating the development of activated, informed individuals who are proficient in self-management skills. ${ }^{1}$ Selfmanagement refers to patients' efforts to engage 
in behaviors to manage their chronic illness. ${ }^{2}$ The emphasis on self-management represents a significant cultural shift in health management, and clinicians and staff may lack confidence introducing and promoting self-management support (SMS). In fact, SMS is the area of disease management least often implemented and most challenging to integrate into usual care..$^{3,4}$

SMS, the efforts of the health care team to promote effective patient engagement in behaviors that positively impact their illness, is increasingly recognized as an important and effective aspect of chronic disease management. ${ }^{5-7}$ Primary care practices, as the loci of coordination of comprehensive care within the patient-centered medical home model defined by the Agency for Healthcare Research and Quality (AHRQ), are being called on to implement SMS. Care managers within practices that have implemented patient-centered medical home transformation are typically engaged in SMS activities. ${ }^{8}$

Despite the recognized importance of SMS as a core feature of the Chronic Care Model (Improving Chronic Illness Care, Seattle, WA), primary care practices struggle with its implementation,,${ }^{9,10}$ especially small to medium-sized practices with little access to external resources for implementation. Additionally, these practices may find that existing tools are not wellsuited to their local settings and patients. In an effort to address this possible barrier, the Implementing Networks' Self-management Tools Through Engaging Patients and Practices (INSTTEPP) trial studied boot camp translation as a method to modify or create locally suited SMS tools.

Boot camp translation was developed by the High Plains Research Network of the University of Colorado School of Medicine (Aurora, CO) and has been applied by others across a number of topics. ${ }^{11,12}$ Boot camp translation translates the language of medical and public health evidence into constructs, messages, and materials that are accessible and actionable by local community members and patients to improve their health. In this paper we report on the main effects to the INSTTEPP intervention of introducing boot camp translation-developed SMS materials on participating practices' patients and staff.

\section{Frequently Used Abbreviations/Acronyms}

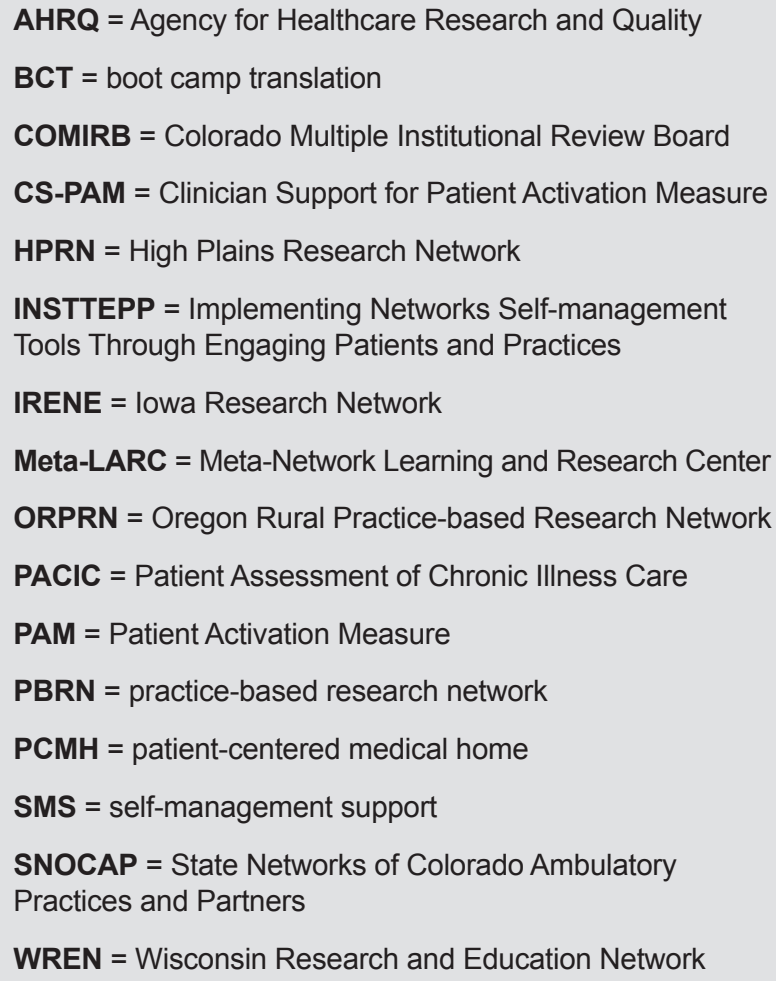

\section{METHODS}

INSTTEPP was designed as a 12-month steppedwedge trial to address whether boot camp translation methods could be used to facilitate primary care practices' implementation or adaptation of SMS tools from AHRQ's SMS library ${ }^{13}$ and assess outcomes on processes of care, activation of practice clinicians and staff, activation of patients, and patients' self-rated health. The study was registered at ClinicalTrials. gov (NCT02815020). Participating practice-based research networks (PBRNs) from the Meta-Network Learning and Research Center (Meta-LARC) consortium were SNOCAP, Iowa Research Network (IRENE), Oregon Rural Practice-based Research Network (ORPRN), and Wisconsin Research and Education Network (WREN). SNOCAP served as the lead coordinating PBRN with support from ORPRN. We chose a stepped-wedge study design for INSTTEPP to ensure that all participating practices received the intervention of introducing the boot camp translation-produced SMS tools. Stepped- 
wedge study design randomizes the order in which the intervention is received or deployed rather than randomizing whether the intervention is received. ${ }^{14-16}$

Recruitment was directed in each of the 4 participating PBRNs toward small to medium-sized practices that likely did not have external support for quality improvement work. However, participating practices were required to have begun implementation of patient-centered medical home features, including the use of a staff member, whether part or full-time, to provide care-manager or health-coaching activities. We solicited letters of support and interest from 6 practices in each PBRN prior to submitting the study proposal to AHRQ, recognizing that practice priorities and capacity for participation could change in the interval period prior to proposal review and ultimate funding. Ultimately, 16 practices, 4 in each participating network, were successfully recruited from among those who had expressed interest and submitted letters of support. Recruited practices represented a distribution of rural, suburban, and urban practices across the networks encompassing the small to medium practice size. Table 1 presents the characteristics of these practices.

Institutional review board (IRB) approval was granted by the Colorado Multiple Institutional Review Board (COMIRB), with the other investigators' academic IRB's ceding to COMIRB.${ }^{17}$ We sought and received a waiver of documentation of consent. Each participant survey had an approved cover page describing informed consent details, and completion and return of surveys was approved to be implied consent. With two exceptions, individual practices, providers, and staff in participating practices were deemed to not be

Table 1. Characteristics of Participating Practices

\begin{tabular}{|c|c|c|c|c|c|}
\hline Practice & Location & $\begin{array}{c}\text { Clinicians / } \\
\text { Staff }\end{array}$ & Ownership & $\begin{array}{c}\text { PCMH } \\
\text { Recognition }\end{array}$ & $\begin{array}{c}\text { Underserved } \\
\text { Patient Population }\end{array}$ \\
\hline ORPRN1 & Rural & 27 & Hospital-owned & Other recognition & Yes \\
\hline ORPRN2 & Suburban & 60 & Totally independent & Other recognition & No \\
\hline ORPRN3 & Rural & 18 & Totally independent & Other recognition & Yes \\
\hline ORPRN4 & Urban & 25 & Totally independent & Other recognition & No \\
\hline WREN1 & Rural & 126 & Physician-owned & None & Yes \\
\hline WREN2 & Urban & 53 & FQHC & Partial or no recognition & Yes \\
\hline WREN3 & Rural & 30 & Integrated system & $\begin{array}{l}\text { Other advanced primary } \\
\text { care redesign }\end{array}$ & Yes \\
\hline WREN4 & Rural & 21 & FQHC & NCQA & Yes \\
\hline IRENE1 & Rural & 21 & Hospital-owned & NCQA & Yes \\
\hline IRENE2 & Urban & 10 & Integrated system & NCQA & No \\
\hline IRENE3 & Rural & 6 & Totally independent & None & Yes \\
\hline IRENE4 & Urban & 101 & Hospital-owned & Partial or no recognition & Yes \\
\hline SNOCAP1 & Suburban & 22 & Totally independent & NCQA & Yes \\
\hline SNOCAP2 & Rural & 18 & Hospital-owned & NCQA & Yes \\
\hline SNOCAP3 & Rural & 10 & Totally independent & NCQA & Yes \\
\hline SNOCAP4 & Suburban & 20 & Totally independent & NCQA & No \\
\hline
\end{tabular}

FQHC, Federally Qualified Health Center; IRENE, lowa Research Network; NCQA, National Committee on Quality Assurance; ORPRN, Oregon Rural Practice-based Research Network; PCMH, patient-centered medical home; SNOCAP, State Networks of Colorado Ambulatory Practices and Partners; WREN, Wisconsin Research and Education Network. 
engaged in the research, rather recruitment of survey and interview participants was conducted by PBRN staff in each network. In several instances, individual practices in Iowa and Oregon were required to gain approval through their local IRB. In-depth details of the IRB processes for this project are reported elsewhere in this issue. ${ }^{17}$

The method we chose for adapting or developing SMS materials to be implemented in INSTTEPP networks was boot camp translation. Boot camp translation is a method that arises from community-based participatory research and engages stakeholders in a longitudinal process to translate evidence, guidelines, and constructs into locally relevant terminology and products. ${ }^{11}$ Boot camp translation had been used prior to INSTTEPP for a variety of clinical topics, including cancer prevention, asthma, and hypertension in
Colorado. ${ }^{12,18-21}$ Each participating PBRN hosted a boot camp translation with individuals from each of their network's 4 participating practices to adapt or develop locally relevant SMS materials at the beginning of their stepped-wedge implementation phase. Given the focus on practice implementation, we designed the boot camp translation groups to include patients, clinicians, and practice staff. A detailed description of the boot camp translations is available elsewhere in this issue. ${ }^{22}$

Randomization of stepped-wedge implementation resulted in the following order of implementation: ORPRN, WREN, IRENE, and finally SNOCAP. Steps marched out in 2-month intervals (blocks), with an initial baseline step followed by 4 sequential implementation steps and a final 2-month tail (Table 2). At each step after the initial baseline time block in

Table 2. Study Timeline

\begin{tabular}{|c|c|c|c|c|c|c|c|c|c|c|c|c|c|c|c|}
\hline & $\begin{array}{c}\text { Months } \\
1-2 \\
\end{array}$ & \multicolumn{3}{|c|}{$\begin{array}{c}\text { Months } \\
3-4\end{array}$} & \multicolumn{3}{|c|}{$\begin{array}{c}\text { Months } \\
5-6 \\
\end{array}$} & \multicolumn{3}{|c|}{$\begin{array}{c}\text { Months } \\
7-8 \\
\end{array}$} & \multicolumn{3}{|c|}{$\begin{array}{c}\text { Months } \\
9-10 \\
\end{array}$} & \multicolumn{2}{|c|}{$\begin{array}{c}\text { Months } \\
11-12\end{array}$} \\
\hline $\begin{array}{l}\text { Implementation } \\
\text { steps }\end{array}$ & $\begin{array}{l}\text { Step } 0 \text { / } \\
\text { baseline }\end{array}$ & \multicolumn{3}{|c|}{ Step 1} & \multicolumn{3}{|c|}{ Step 2} & \multicolumn{3}{|c|}{ Step 3} & \multicolumn{3}{|c|}{ Step 4} & \multicolumn{2}{|c|}{ Step 5} \\
\hline ORPRN & & \multicolumn{3}{|c|}{ boot camp } & & & & & & & & & & & \\
\hline WREN & & & & & \multicolumn{3}{|c|}{ boot camp } & & & & & & & & \\
\hline IRENE & & & & & & & & \multicolumn{3}{|c|}{ boot camp } & & & & & \\
\hline SNOCAP & & & & & & & & & & & & ot cal & & & \\
\hline \multicolumn{16}{|c|}{$\begin{array}{l}\text { Patient participant } \\
\text { survey cohorts }\end{array}$} \\
\hline ORPRN & 1 & 1 & 1 & 2 & 2 & 2 & 3 & 3 & 3 & 4 & 4 & 4 & 5 & 5 & 5 \\
\hline WREN & 1 & 1 & 1 & 2 & 2 & 2 & 3 & 3 & 3 & 4 & 4 & 4 & 5 & 5 & 5 \\
\hline IRENE & 1 & 1 & 1 & 2 & 2 & 2 & 3 & 3 & 3 & 4 & 4 & 4 & 5 & 5 & 5 \\
\hline SNOCAP & 1 & 1 & 1 & 2 & 2 & 2 & 3 & 3 & 3 & 4 & 4 & 4 & 5 & 5 & 5 \\
\hline \multicolumn{16}{|c|}{$\begin{array}{l}\text { Practice key } \\
\text { informant interviews }\end{array}$} \\
\hline ORPRN & & \multicolumn{3}{|c|}{ baseline } & \multicolumn{3}{|c|}{ follow-up } & & & & & & & & \\
\hline WREN & & & & & \multicolumn{3}{|c|}{ baseline } & \multicolumn{3}{|c|}{ follow-up } & & & & & \\
\hline IRENE & & & & & & & & \multicolumn{3}{|c|}{ baseline } & \multicolumn{3}{|c|}{ follow-up } & \multirow{2}{*}{\multicolumn{2}{|c|}{ follow-up }} \\
\hline SNOCAP & & & & & & & & & & & & aselir & & & \\
\hline
\end{tabular}

Unshaded cells indicate that the network's practices and their patient cohorts were in a "control" condition. Shaded cells indicate when practices and cohorts were considered to be in an "intervention" condition.

${ }^{*}$ Numbers indicate patient participant cohort for each network. 
which all practices were in control phase, 1 PBRN (4 practices) "crossed over" from control to intervention phase until all practices were in intervention phase. ${ }^{14}$ The boot camp translations were held sequentially in each network to adapt and design SMS materials and were followed by implementation of those materials in each participating network's 4 practices. Each step included data collection from patients in cohorts, as shown in Table 2, and practice staff and clinicians across all steps.

\section{Participants and Data Collection}

Office Staff Recruitment: Practice staff (nurses and medical assistants) and clinicians were recruited at each of the 16 participating practices to complete 5 surveys, one during each 2-month "step" of the design. We sought to recruit a minimum of 5 clinician/ staff participants from each practice to complete the repeated survey consisting of the Clinician Support for Patient Activation Measure (CS-PAM) ${ }^{23}$ and a 15-item instrument assessing intent to implement SMS based on the theory of planned behavior. ${ }^{24}$ Clinician/staff surveys were administered via email invitation through the University of Colorado's implementation of web-based Research Electronic
Data Capture (REDCap) software, unless practices requested otherwise, in which case paper surveys were used.

Patient Recruitment: For each 2-month step of the design, we recruited 4 patients from each practice to complete 3 serial surveys over a 3-month period. The 3 patient survey waves were slightly longer than the 2-month implementation step in which they were embedded to capture the impact of the practice level work of implementing the self-management tools following the completion of the 2-month boot camp translations. Patients, aged 18 to 70 years, who had at least one chronic disease and were early in the process of working with participating practices' care management staff were eligible. Coordinators at each PBRN solicited names and contact information from practice staff for eligible patients, and they conducted recruitment phone calls in random order with each eligible patient on a practice's list until 4 were recruited for the upcoming step. We sought to assess outcomes of patient activation, which has been associated with self-management behavior, ${ }^{25}$ patients' perceptions of their care related to SMS, and their own health.

Table 3. Patient Assessment of Chronic Illness Care (PACIC) Items

\section{My health care team members at this practice...}

1. Showed me how what I did to take care of myself influenced my chronic condition(s).

2. Asked to talk about my goals in caring for my condition(s).

3. Helped me set specific goals to improve my eating or exercise.

4. Gave me a copy of my treatment plan.

5. Encouraged me to go to a specific group or class to help me cope with my chronic condition.

6. Asked me questions, either directly or on a survey, about my health habits.

7. Thought about my values, beliefs, and traditions when he/she recommended treatments to me.

8. Helped me make a treatment plan that I could carry out in my daily life.

9. Helped me plan ahead so I could take care of my condition(s) or myself even in hard times.

(Participants recorded responses on a 5-point Likert scale ranging from "none of the time" to "always.")

CDC Healthy Days Core Module question:

Would you say that in general your health is: Excellent (1), Very Good (2), Good (3), Fair (4), or Poor (5)?

CDC, Centers for Disease Control and Prevention. 
Therefore, patient surveys consisted of the Patient Activation Measure (PAM), ${ }^{26} 9$ items related to self-management from the Patient Assessment of Chronic Illness Care (PACIC), ${ }^{27}$ as shown in Table 3, and the self-rated health question from the Centers of Disease Control and Prevention's Healthy Days Core Module (https:/www.cdc.gov/hrqol/hrqol14 measure.htm). Patient surveys were administered either via the University of Colorado's REDCap system or via mailed paper survey when requested by the patient participant.

In addition to these quantitative surveys of patients and practice clinicians and staff, key informant interviews and observations were conducted with practice staff approximately 1 month after the boot camp translation kickoff retreat and again within about 2 weeks of the final boot camp translation phone call. Details and analysis of this qualitative data are presented in a separate paper published in this issue. ${ }^{28}$

\section{Statistical Analysis}

Descriptive statistics were generated for patient sociodemographic and clinical measures as well as practice characteristics. To understand the potential for confounding due to associations among practice characteristics, bivariate relationships were examined using chi-squared tests and t-tests.

Patient-reported outcomes over time (at 0,1 , and 2 months after enrollment) were analyzed using general linear mixed models that are both longitudinal and hierarchical (PROC MIXED program, SAS Institute Inc., Cary, NC) with random effects for patient and practice. Patient-level variables included age, gender, number of chronic conditions, survey $(0,1,2)$, and study group (control vs intervention). At the patient level, study group was determined by when the patient entered the cohort and whether practice was in the control or intervention phase at that time. A survey $x$ group term was included to test for differential trend over time between control and intervention patients. A term for time block (ie, step) was included to adjust for temporal trend. ${ }^{14}$

Clinician- and staff-level outcomes also were analyzed using general linear mixed models with random effects for the individual respondent and the practice. An indicator variable was included for clinician vs staff; other level variables included survey $(0,1,2,3,4,5)$, group (time-varying covariate at the clinician/staff level), and a survey $\times$ group interaction term to determine if trajectories changed after the practice converted to implementation phase. All available data were used for all analyses. Analyses were performed using SAS Version 9.4 (SAS Institute Inc.).

\section{RESULTS}

\section{Patient Participants}

Table 4 presents the baseline characteristics of the patients participating during the intervention and control periods. Demographics and prevalence of chronic illness overall are consistent with what was expected from patients entering work with a care manager. Patient participants during intervention cohorts had significantly poorer self-rated health and were significantly more likely to have diabetes $(55 \%$ vs 39\%). Out of a targeted 320 patient participants, 297 , or $93 \%$, completed the first of the 3 surveys in each survey wave, with 289 and 281 completing the second and third surveys, respectively, or $5 \%$ attrition over the measurement period.

\section{Clinician- and Staff-Level Results}

Table 5 presents the survey means and analysis of the CS-PAM and theory of planned behavior measures that were collected from the clinicians and practice staff in participating clinics. There was attrition noted in the participants of these surveys over time. No significant intervention effects were observed.

\section{Patient Outcomes}

Table 6 presents the patient participant outcomes after adjustment for age, gender, number of chronic conditions, and time block. There was no significant difference in change over time in PAM scores between intervention and control patients over the 3 surveys (survey $\times$ arm: $\mathrm{F}(1,840)=0.87, \mathrm{P}=0.3515$ ). There was a significant difference seen in the change for PACIC items; control subjects experienced a slight decline from a mean of the summed responses of 31.32 to 30.20 , and intervention subjects reported an increase from 30.20 to 32.32 (survey $\times$ arm: $\mathrm{F}(1,797)=16.75, \mathrm{P}<0.001)$. There was a similar significant difference seen in self-reported health 
Table 4. Patient Participant Characteristics

\begin{tabular}{|c|c|c|c|c|c|}
\hline Variable & Data set, $\mathrm{N}$ & Level & Control, \% (n) & Intervention, \% (n) & $P$ \\
\hline \multirow[t]{2}{*}{ Sex } & 297 & Female & $64 \%(96)$ & $57 \%(83)$ & 0.24 \\
\hline & & Male & $36 \%(55)$ & $43 \%(63)$ & \\
\hline \multirow[t]{3}{*}{ Education } & 294 & $<\mathrm{HS}$ & $2 \%(3)$ & $6 \%(9)$ & 0.17 \\
\hline & & HS & $27 \%(40)$ & $28 \%(40)$ & \\
\hline & & $>\mathrm{HS}$ & $71 \%(107)$ & $66 \%(95)$ & \\
\hline \multirow[t]{3}{*}{ Employment } & 243 & Employed & $53 \%(63)$ & $52 \%(65)$ & 0.15 \\
\hline & & Not employed & $7 \%(8)$ & $14 \%(17)$ & \\
\hline & & Retired & $40 \%(48)$ & $34 \%(42)$ & \\
\hline \multirow[t]{2}{*}{ Health } & 293 & Exc/VG/G & $66 \%(99)$ & $52 \%(75)$ & 0.01 \\
\hline & & Fair/Poor & $34 \%(50)$ & $48 \%(69)$ & \\
\hline \multicolumn{6}{|l|}{ Chronic (Yes) } \\
\hline Diabetes & 296 & & $39 \%(59)$ & $55 \%(81)$ & 0.01 \\
\hline Arthritis & 296 & & $36 \%(54)$ & $40 \%(59)$ & 0.43 \\
\hline High BP & 296 & & $63 \%(94)$ & $62 \%(90)$ & 0.86 \\
\hline Heart disease & 296 & & $16 \%(24)$ & $11 \%(16)$ & 0.20 \\
\hline Lung disease & 296 & & $9 \%(14)$ & $12 \%(18)$ & 0.41 \\
\hline Depression & 296 & & $43 \%(64)$ & $45 \%(65)$ & 0.75 \\
\hline Chronic pain & 296 & & $23 \%(35)$ & $32 \%(47)$ & 0.09 \\
\hline Heart failure & 296 & & $2 \%(3)$ & $5 \%(7)$ & 0.18 \\
\hline Chronic (other) & 296 & & $29 \%(43)$ & $27 \%(40)$ & 0.81 \\
\hline Chronic (none) & 296 & & $5 \%(7)$ & $5 \%(8)$ & 0.75 \\
\hline
\end{tabular}

BP, blood pressure; Exc/G/VG, excellent/good/very good; HS, high school diploma.

over the 3 surveys. Control participants reported virtually no change in self-reported health, from 3.17 to 3.16 , whereas intervention participants reported a change from 3.35 to 3.1 (survey $\times$ arm: $F(1$, 832 ) $=4.89, \mathrm{P}=0.0273$ ), with lower scores indicating better health. Healthy days trajectories did not differ significantly over time between groups (survey $\times$ group: $\mathrm{F}(1,833)=0.08, \mathrm{P}=0.7763)$.

\section{DISCUSSION}

Self-management support is a critical component of care to improve chronic disease outcomes; however, engaging patients in key elements such as goal setting and action planning challenge many practices. The INSTTEPP project utilized the boot camp translation method to engage clinicians, staff, and their patients in a process of co-learning and co-creation of 4 networkspecific SMS tools across 4 PBRNs and 16 small to medium-sized primary care practices. Each boot camp translation group learned the principles of SMS and evaluated the existing tools in the AHRQ library. As reported in a companion paper, through the boot camp translation process, each PBRN created its own SMS tool that represented its unique perspective on the key elements of SMS. ${ }^{22}$

While activation as measured by PAM did not show greater improvement among intervention patients, process of care as measured by 9 items from the PACIC did show a significantly greater amount of improvement, as did self-rated health. Interestingly, no significant changes were observed in clinician and 
Table 5. Clinician and Staff Participant Outcome Means and Comparisons

\begin{tabular}{|c|c|c|c|c|}
\hline Measure & Survey (N) & Controls & Intervention & Differential Intervention Effect \\
\hline \multirow[t]{5}{*}{ CS-PAM } & $1(89)$ & 81.89 & & \\
\hline & $2(67)$ & 81.96 & 80.50 & \\
\hline & $3(65)$ & 82.04 & 81.03 & \\
\hline & $4(61)$ & 82.11 & 81.56 & \\
\hline & $5(55)$ & & 82.09 & $F(1,317)=0.10, P=0.7464$ \\
\hline \multicolumn{5}{|c|}{ Theory of planned behavior } \\
\hline \multirow[t]{5}{*}{ Knowledge } & $1(89)$ & 0.54 & & \\
\hline & $2(67)$ & 0.61 & 0.57 & \\
\hline & $3(65)$ & 0.67 & 0.66 & \\
\hline & $4(61)$ & 0.74 & 0.75 & \\
\hline & $5(55)$ & & 0.85 & $F(1,314)=0.25, P=0.6182$ \\
\hline \multirow[t]{5}{*}{ Affective } & $1(89)$ & 1.69 & & \\
\hline & $2(67)$ & 1.74 & 1.45 & \\
\hline & $3(65)$ & 1.79 & 1.57 & \\
\hline & $4(61)$ & 1.83 & 1.70 & \\
\hline & $5(55)$ & & 1.83 & $F(1,313)=0.54, P=0.4630$ \\
\hline \multirow[t]{5}{*}{ Intention 1} & $1(89)$ & 2.28 & & \\
\hline & $2(67)$ & 2.24 & 2.01 & \\
\hline & $3(65)$ & 2.20 & 2.10 & \\
\hline & $4(61)$ & 2.15 & 2.19 & \\
\hline & $5(55)$ & & 2.28 & $F(1,313)=1.50, P=0.2213$ \\
\hline \multirow[t]{5}{*}{ Intention 2} & $1(89)$ & 2.22 & & \\
\hline & $2(67)$ & 2.14 & 1.92 & \\
\hline & $3(65)$ & 2.07 & 2.01 & \\
\hline & $4(61)$ & 1.99 & 2.09 & \\
\hline & $5(55)$ & & 2.18 & $F(1,308)=2.04, P=0.1542$ \\
\hline \multirow[t]{5}{*}{ Perception } & $1(89)$ & 1.51 & & \\
\hline & $2(67)$ & 1.54 & 1.31 & \\
\hline & $3(65)$ & 1.57 & 1.39 & \\
\hline & $4(61)$ & 1.59 & 1.47 & \\
\hline & $5(55)$ & & 1.62 & $F(1,314)=0.29, P=0.5882$ \\
\hline \multirow[t]{5}{*}{ Social } & $1(89)$ & 2.00 & & \\
\hline & $2(67)$ & 2.05 & 1.98 & \\
\hline & $3(65)$ & 2.09 & 2.04 & \\
\hline & $4(61)$ & 2.14 & 2.11 & \\
\hline & $5(55)$ & & 2.17 & $F(1,315)=0.03, P=0.8637$ \\
\hline
\end{tabular}

CS-PAM, Clinician Support for Patient Activation Measure. 
Table 6. Patient Outcomes Adjusted for Age, Gender, Number of Chronic Conditions, and Time Block

\begin{tabular}{lcccc}
\hline Measure & Survey & Controls & Intervention & Differential Intervention Effect \\
\hline Patient Activation Measure & 1 & 66.72 & 66.08 & $\mathrm{~F}(1,840)=0.87, \mathrm{P}=0.3515$ \\
& 2 & 66.79 & 66.72 & \\
Process of care (per PACIC) & 3 & 66.86 & 67.36 & $\mathrm{~F}(1,797)=16.75, \mathrm{P}<0.0001$ \\
& 1 & 31.32 & 30.20 & \\
Self-reported health* & 2 & 30.76 & 31.25 & $\mathrm{~F}(1,832)=4.89, \mathrm{P}=0.0273$ \\
& 3 & 30.20 & 32.32 & \\
\hline
\end{tabular}

*Lower score is better so declining scores indicate improvement.

PACIC, Patient Assessment of Chronic Illness Care.

staff measures as they transitioned from control to intervention steps, although there were slight trends in the expected direction.

The changes seen in intervention patient participants' PACIC scores and self-rated health compared to controls are an important sign of the impact of the boot camp translation process and the efforts to implement the SMS tools designed in the boot camp groups. The success of boot camp translation in tailoring SMS to local settings reflects findings reported by Taylor et al. ${ }^{29}$ Through every implementation step in each PBRN, new enrolled patient participants were being engaged in their practice's new efforts at SMS. Over the 3 months of patient participation, intervention patients experienced subtle improvement in their practices' approach to SMS, reflected in their ratings of PACIC items that measure goal setting and treatment planning. Similarly, intervention patients' ratings of their own health showed improvement over the 3 months of measurement.

\section{Limitations}

A significant limitation of the INSTTEPP study was the extremely short time frame of 12 months for the actual study. This impacted the boot camp translation process, which was abbreviated from a typical 6- to 9-month process to a much shorter 2-month one.
Additionally, the observation periods were relatively short, especially for those networks and practices that entered the implementation phase later in the project. Another limitation was the high dropout rate among clinician and staff participants. This clearly impacted our ability to measure changes in their attitudes and behaviors around SMS. Finally, we were struck by our inability to detect a significant change in the PAM responses. There is limited existing data on sensitivity to change for PAM, ${ }^{25,30}$ and while it clearly is associated with key outcomes cross-sectionally, across our moderately sized sample we did not see changes that paralleled changes in our other outcomes. The small significant changes we did observe and the lack of significant change in PAM could be due to the brief 3-month observation period for our patient participants.

\section{CONCLUSIONS}

In summary, despite a relatively constrained implementation and study period, we were able to demonstrate significant improvements in key patient outcomes as a result of applying the engagementbased boot camp translation method of translating key concepts and messages of self-management support for small to medium-sized primary care practices and their patients. These promising results need replication in a larger and longer trial. 


\section{Patient-Friendly Recap}

- Self-management, or a patient's own steps to manage his or her chronic illness, is an important aspect of improving overall care.

- The authors tested a process called boot camp translation that brought patients, their clinicians, and primary care practices together to design tools to help patients improve their self-management.

- Patients in participating practices reported improvements in their own health and in the care provided by their practices.

- These results should inform larger studies testing how patient input to design tools and care can improve patient health.

\section{Acknowledgments}

Mayo Clinic Health System (Tomah, WI); Milwaukee Health Services, Inc. (Milwaukee, WI); Northlakes Community Clinic (Iron River, WI); Richland Medical Center (Richland Center, WI); Family Medical Group, NE, P.C. (Portland, OR); Northwest Primary Care Sellwood Clinic (Portland, OR); Springfield Family Physicians (Springfield, OR); Winding Waters Clinic (Enterprise, OR); Akron Mercy Medical Clinic (Akron, IA); Red Haw Family Medical Center, P.C. (Chariton, IA); Family Medicine Clinic, University of Iowa Hospitals and Clinics (Iowa City, IA); Family Care Southwest (Littleton, CO); MidValley Family Practice (Basalt, CO); Westminster Medical Clinic (Westminster, CO); Yuma Clinic, (Yuma, CO).

\section{Author Contributions}

Study design: Nease, Hahn, Levy, Westfall, Fagnan. Data acquisition or analysis: Nease, Dickinson, Michaels. Manuscript drafting: Nease, Dickinson. Critical revision: all authors.

\section{Conflicts of Interest}

None.

\section{Funding Sources}

This research was funded by Agency for Healthcare Research and Quality (AHRQ) grant 1R18HS022491-01. Infrastructure support (ie, Meta-LARC) was funded by AHRQ grant IP30HS021639-01.

\section{References}

1. Bodenheimer $\mathrm{T}$, Wagner $\mathrm{EH}$, Grumbach $\mathrm{K}$. Improving primary care for patients with chronic illness. JAMA. 2002;288:1775-9. CrossRef

2. Lorig KR, Holman H. Self-management education: history, definition, outcomes, and mechanisms. Ann Behav Med. 2003;26:1-7. CrossRef
3. Glasgow RE, Davis CL, Funnell MM, Beck A. Implementing practical interventions to support chronic illness selfmanagement. Jt Comm J Qual Saf. 2003;29:563-74. CrossRef

4. Coleman K, Mattke S, Perrault PJ, Wagner EH. Untangling practice redesign from disease management: how do we best care for the chronically ill? Annu Rev Public Health. 2009;30:385-408. CrossRef

5. Warsi A, Wang PS, LaValley MP, Avorn J, Solomon DH. Self-management education programs in chronic disease: a systematic review and methodological critique of the literature. Arch Intern Med. 2004;164:1641-9. CrossRef

6. Glasgow RE, Funnell MM, Bonomi AE, Davis C, Beckham $\mathrm{V}$, Wagner EH. Self-management aspects of the improving chronic illness care breakthrough series: implementation with diabetes and heart failure teams. Ann Behav Med. 2002;24:80-7. CrossRef

7. Bodenheimer T, Lorig K, Holman H, Grumbach K. Patient self-management of chronic disease in primary care. JAMA. 2002;288:2469-75. CrossRef

8. Taylor EF, Machta RM, Meyers DS, Genevro J, Peikes DN. Enhancing the primary care team to provide redesigned care: the roles of practice facilitators and care managers. Ann Fam Med. 2013;11:80-3. CrossRef

9. Kennedy A, Bower P, Reeves D, et al. Implementation of self management support for long term conditions in routine primary care settings: cluster randomised controlled trial. BMJ. 2013;346:f2882. CrossRef

10. van Dijk-de Vries A, van Bokhoven MA, Winkens B, et al. Lessons learnt from a cluster-randomised trial evaluating the effectiveness of self-management support (SMS) delivered by practice nurses in routine diabetes care. BMJ Open. 2015;5(6):e007014. CrossRef

11. Norman N, Bennett C, Cowart S, et al. Boot camp translation: a method for building a community of solution. J Am Board Fam Med. 2013;26:254-63. CrossRef

12. Westfall JM, Zittleman L, Felzien M, et al. Reinventing the wheel of medical evidence: how the boot camp translation process is making gains. Health Aff (Millwood). 2016;35:613-8. CrossRef

13. Agency for Healthcare Research and Quality. Selfmanagement support. Content last reviewed January 2018. http://www.ahrq.gov/professionals/prevention-chronic-care/ improve/self-mgmt/index.html. Accessed July 27, 2018.

14. Hussey MA, Hughes JP. Design and analysis of stepped wedge cluster randomized trials. Contemp Clin Trials. 2007;28:182-91. CrossRef

15. Brown CA, Lilford RJ. The stepped wedge trial design: a systematic review. BMC Med Res Methodol. 2006;6:54. CrossRef

16. Mdege ND, Man MS, Taylor nee Brown CA, Torgerson DJ. Systematic review of stepped wedge cluster randomized trials shows that design is particularly used to evaluate interventions during routine implementation. $J$ Clin Epidemiol. 2011;64:936-48. CrossRef

17. Daly JM, Weiner Harrod T, Judge K, et al. Practice-based research networks ceding to a single institutional review board. J Patient Cent Res Rev. 2018;5:304-10.

18. Norman N, Cowart S, Felzien M, et al. Testing to prevent colon cancer: how rural community members took on a communitybased intervention. Ann Fam Med. 2013;11:568-70. CrossRef 
19. Bender BG, Dickinson P, Rankin A, Wamboldt FS, Zittleman L, Westfall JM. The Colorado Asthma Toolkit Program: a practice coaching intervention from the High Plains Research Network. J Am Board Fam Med. 2011;24:240-8. CrossRef

20. DeAlleaume L, Parnes B, Zittleman L, et al. Success in the Achieving CARdiovascular Excellence in Colorado (A CARE) home blood pressure monitoring program: a report from the Shared Networks of Colorado Ambulatory Practices and Partners (SNOCAP). J Am Board Fam Med. 2015;28:548-55. CrossRef

21. Zittleman L, Emsermann C, Dickinson M, et al. Increasing colon cancer testing in rural Colorado: evaluation of the exposure to a community-based awareness campaign. $B M C$ Public Health. 2009;9:288. CrossRef

22. Simpson MJ, Daly JM, Fernald DH, et al. How to translate self-management support tools into clinical practice. $J$ Patient Cent Res Rev. 2018;5:276-86.

23. Hibbard JH, Collins PA, Mahoney E, Baker LH. The development and testing of a measure assessing clinician beliefs about patient self-management. Health Expect. 2010;13:65-72. $\underline{\text { CrossRef }}$

24. Young HM, Lierman L, Powell-Cope G, Kasprzyk D, Benoliel JQ. Operationalizing the theory of planned behavior. Res Nurs Health. 1991;14:137-44. CrossRef
25. Hibbard JH, Mahoney ER, Stock R, Tusler M. Do increases in patient activation result in improved self-management behaviors? Health Serv Res. 2007;42:1443-63. CrossRef

26. Hibbard JH, Mahoney ER, Stockard J, Tusler M. Development and testing of a short form of the patient activation measure. Health Serv Res. 2005;40:1918-30. CrossRef

27. Glasgow RE, Wagner EH, Schaefer J, Mahoney LD, Reid RJ, Greene SM. Development and validation of the Patient Assessment of Chronic Illness Care (PACIC). Med Care. 2005;43:436-44. CrossRef

28. Fernald DH, Simpson MJ, Nease DE Jr, et al. Implementing community-created self-management support tools in primary care practices: multimethod analysis from the INSTTEPP study. J Patient Cent Res Rev. 2018;5:267-75.

29. Taylor SJC, Pinnock H, Epiphaniou E, et al. A rapid synthesis of the evidence on interventions supporting self-management for people with long-term conditions: PRISMS - Practical systematic Review of Self-Management Support for longterm conditions. Health Serv Deliv Res. 2014;2(53):1-580. CrossRef

30. Greene J, Hibbard JH, Sacks R, Overton V, Parrotta CD. When patient activation levels change, health outcomes and costs change, too. Health Aff (Millwood). 2015;34:431-7. CrossRef

(C) 2018 Aurora Health Care, Inc. 